\title{
The Effect of L2 Experience on the Perceptual Assimilation of British English Monophthongs to Thai Monophthongs by L2 Thai Learners
}

\author{
Patchanok Kitikanan ${ }^{1}$ \\ ${ }^{1}$ English Department, Faculty of Humanities, Naresuan University, Phitsanulok, Thailand \\ Correspondence: Patchanok Kitikanan, English Department, Faculty of Humanities, Naresuan University, \\ Phitsanulok, Thailand, 65000.
}

Received: March 15, 2020

Accepted: April 8, 2020

Online Published: April 9, 2020

doi: 10.5539/elt.v13n5p1

URL: https://doi.org/10.5539/elt.v13n5p1

\begin{abstract}
Perceptual assimilation is a well-known task; however, there is no study on the assimilation pattern of the English monophthongs by L2 Thai learners. The aims of this study are to explore the perceptual assimilation patterns of the British English monophthongs to Thai monophthongs by L2 Thai learners and to examine the effect of L2 experience on this perception. The target British English sounds were /i:, I, e, æ, b, a:, o:, v, u:, $\Lambda$, 3:/ in $/ \mathrm{bVt} /$ context. The Thai listeners performed an assimilation task by matching these British English monophthongs with their L1 Thai monophthongs. The results showed no difference in the assimilation patterns between the high-experienced and low-experienced groups in the perception of the English /I, e, a:, ৩:, $,, \Lambda, 3: /$ The degree of the perceived similarity in the matching of these vowels to the Thai sound categories between these two groups was not significantly different from one another either. However, English /e/ was mostly perceived as Thai /e/ in the high-experienced group to a greater degree than the low-experienced group. The findings also showed the difference in the assimilation patterns between these two groups, i.e. for English /æa, i:, $\mathrm{u}$ :, $\mathrm{p} /$ suggesting the importance of the L2 experience in the exploration of the L2 speech learning research. The implication for L2 sound learning of this study is that having higher number of phonemes in the L1 phonological system than that in the L2 one is less important than the L2 experience.
\end{abstract}

Keywords: perceptual assimilation, British English, monophthongs, Thai, L2 experience

\section{Introduction}

\subsection{Rationale of the Study}

One of the main aims of second language (L2) phonology is to understand the mechanisms associated with learning L2 sounds. It is believed that the learning of the L2 sounds are filtered via the first language (L1) sound categories (Best, 1995; Best \& Tyler, 2007; Escudero, 2009; Flege, 1995). The exploration of the similarity between the L1 sounds and the L2 sounds can be done in many ways, such as via acoustic measurements, comparison of the phonological systems of L1 and L2, and by exploring the perceived similarity between the L1 and the L2 sounds by L2 learners. Among these methods, the use of the perceptual assimilation task to explore the degree of similarity between the target L2 sounds and the L1 sounds is the most well-known as it is the investigation of the similarity between the L1 and L2 sounds based on the perception of the learner. In the perceptual assimilation task, there are two processes: investigating the perceived similarity with the classification of the L2 sounds in terms of the closest L1 sounds (assimilation task) and exploring the degree of the similarity between L1 and L2 sounds using a rating scale (goodness rating). This task is commonly used to predict the results for the identification task and discrimination task which are the tasks to explore the performance in L2 perception. The performance in the identification task is commonly accounted with the Speech Learning Model (SLM) (Flege, 1995) as the task and the model has the focus on individual sound. The findings from the discrimination task could be accounted by the Perceptual Assimilation Model-L2 (PAM-L2) (Best \& Tyler, 2007) as the task and the model has the focus on sound contrast. According to PAM-L2, the assimilation of the L2 sounds to L1 sound(s) can be divided into four types: Two-category (TC) when two L2 sounds are perceived as different L1 sounds, Category-goodness (CG) when two L2 sounds are matched with one sound in L1 with different degree, Single-category (SC) when the L2 sounds are perceived as one sound in L1 with similar degree and Uncategorised-uncategorised (UU) when the L2 sounds cannot be assigned to any L1 category. The pair of English monophthongs cannot be UU assimilation for the L1 Thai learners as there was also monophthongs in 
Thai.

Up until now, there are many studies on the perceptual assimilation of the English vowels to L1 vowel categories (e.g., Cebrian, 2019; Levy, 2009). For example, Cebrian (2019) explored the perceived similarity between vowels in Standard British English and Spanish vowels. The results showed that English diphthongs were consistently perceived as closer to Spanish diphthongs than to Spanish monophthongs. Although there are many studies on the perceived similarity between the English vowels and the L1 vowels, the number of perceptual assimilation research that includes the experience of the L2 (e.g., Kitikanan, 2017; Levy, 2009) is small despite the L2 experience has shown to be important in the L2 phonological learning. For example, in the study of Kitikanan (2017), the perceived similarity between English fricatives and related sounds, and L1 Thai categories was investigated. Many findings of this study showed the influence of the L2 experience over the perceptual assimilation patterns, such as when the high-experienced group perceived English /z/ as similar to Thai /s/ in a higher degree than the low-experienced group in all vowel contexts. This suggests that the degree of perceived similarity between L1 and L2 sounds varies according to the L2 experience. In the study of Levy (2009), the perceptual assimilation of Parisian French (PF) front rounded vowels $/ y /$ and $/ œ /$ were investigated for the effects of L2 experience and consonant context as perceived by American English (AE) learners of French. The AE learners were divided into three groups according to their French experience: no experience, formal instruction, formal-plus-immersion experience. The consonantal contexts tested were bilabial and alveolar contexts. The finding of the assimilation patterns for $\mathrm{PF} / \mathrm{y} /$ showed that although there was no effect of L2 experience of the assimilation patterns for $\mathrm{PF} / \mathrm{y} /$ in alveolar context, the listeners with formal-plus-immersion experience matched $\mathrm{PF} / \mathrm{y} /$ to $\mathrm{AE} / \mathrm{j} /$ less often than the listeners with only formal experience, followed by naïve listeners. This suggests that L2 learners with higher L2 experience can discern differences between L1 and L2 sounds than those with lower L2 experience.

In addition, in most studies where the perceptual assimilation is based on the measure of the L2 sounds with the closest L1 sounds, there were fewer L1 sounds than L2 sounds within the same category (e.g., Cebrian, 2019; Strange, Bohn, Trent, \& Nishi, 2004), such as having fewer fricatives in L1 than fricatives in L2. For example, in the study of Cebrian (2019), the perceptual assimilation of British English vowels to Spanish monophthongs and diphthongs was investigated. When comparing the number of British English monophthongs which are L2 to the number of Spanish monophthongs which are L1, the number of British English monophthongs was 11 whereas the number of Spanish monophthongs was five. Within the same category, higher number of L1 sounds compared to L2 sounds might facilitate the L2 sound learning, especially in perception. The variability of the L1 sounds of the same category as the L2 sounds might provide more alternatives for the assimilation patterns resulting in the less overlapped assimilation patterns. This should benefit the performance of the identification and discrimination tasks. One interesting question here is whether all L2 learners, regardless of L2 experience, benefit from this higher number of L1 sounds than the number of the L2 sounds in the same category.

Regarding the study on English vowel learning by L2 Thai learners, most previous studies were carried out on the production of English vowels using acoustic measurements (Kallayanamit, 2016; Tsukada, 2009). For example, Tsukada (2009) carried out an investigation on durational characteristics of English vowels /i:/ and /I/ produced by Japanese, Thai and Australian English. The words were monosyllabic ending with /p, t, k/. For /i:/, the stimuli were 'beep,' 'beat,' 'beak,' 'feet,' 'seep,' 'seat' and 'seak.' For /I/, they were 'kit,' 'kick,' 'lip,' 'lit,' 'lick,' 'sip,' 'sit,' and 'sick.' The results showed that the mean durations of /i:/ and / $\mathrm{I}$ for Australian English speakers were $182 \mathrm{~ms}$ and $122 \mathrm{~ms}$ whereas those for Thai speakers were $213 \mathrm{~ms}$ and $93 \mathrm{~ms}$. There was no significant difference of the duration for $/ \mathrm{i}$ :/ being produced by these two groups, nor that of $/ \mathrm{I} /$, and the durations of these two vowels were significantly different in these two groups. However, Tsukada suggested that Thai speakers should be aware that the English short vowels are not as short as the Thai short vowels, and that the English long vowels are not as long as the Thai long vowel counterparts either.

The study on English vowel perception by L2 Thai learners (e.g., Kallayanamit, 2010; Nusartlert \& Tongpoonpatanasorn, 2015) is rare. For example, in the study of Nusartlert and Tongpoonpatanasorn (2015), the perception of British English /u:/ and / / by L2 Thai learners was investigated with identification and discrimination tasks. They found that female learners were better at identifying and discriminating L2 English sounds than male learners. The study of Kallayanamit (2010) examined the perception of American English

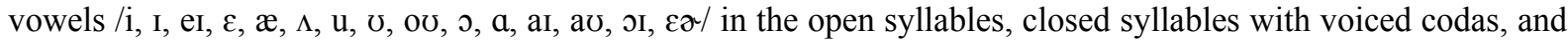
closed syllables with voiceless codas. The finding showed that L2 Thai learners were proficient in identifying /av, aI, गI, æ/ (over 75\% accurate for each) while the correct identification scores were low in the rest of the target vowels. The correct identification score of monophthongs was less than that of diphthongs. Regarding the vowel qualities, the findings showed that the back vowels were more difficult than the front vowels; the rounded 
vowels were more difficult than the unrounded vowel; the high vowels were more difficult than the low vowels; and the short (or lax) vowels were more difficult than the long (or tense) ones.

Despite previous studies on English vowel perception by L2 Thai learners, this study is the first study investigating the assimilation patterns of English vowels to Thai vowels as perceived by L2 Thai learners. There are twelve monophthongs in British English: /i:, I, e, æ, p, a:, o:, v, u:, $\Lambda$, 3:, ə/. From these twelve monophthongs, the schwa /ə/ has no unique representation in spelling (Roach, 2004) as it is likely to occur only in the unstressed syllable; hence it is excluded in this study. Thai has eighteen monophthongs which are composed of nine pairs: /i, i:, e, e:, æ, æ:, o, o:, a, a:, u, u:, ə, ə:, o, o:, w, w:/. The sounds in each pair are mainly contrastive with length. The L2 Thai learners were asked to identify British English monophthongs in terms of Thai monophthong categories and rate them on the degree of perceived similarity. There were two groups of the Thai learners: high-experienced and low-experienced. With the larger number of monophthongs in Thai, it is interesting to investigate whether this high number of monophthongs is the dominant factor to the L2 experience, i.e. both high-experienced and low-experienced Thai learners might not have overlapping matching of the English monophthongs with the Thai monophthongs.

Apart from that, this study is a part of the big project investigating the perception of British English monophthongs by L2 Thai learners. It consists of three experiments: perceptual assimilation task, L2 sound identification task and L2 sound discrimination task. The aim of this study is to explore the perceptual assimilation patterns of the English monophthongs with the Thai monophthongs and the effect of L2 experience. This is the first experiment of the research project. The results from this study will be used to generate hypotheses for the identification task and for the discrimination task of English monophthongs as perceived by L2 Thai learners. It is expected that the increase in understanding the perceptual assimilation resulting from this study of British/Thai monophthongs will be helpful to teachers of L2 learners.

\subsection{Research Questions and Hypotheses}

As the main aim of this study is to explore the perceptual assimilation patterns of English monophthongs with the Thai monophthongs and the effect of L2 experience, there are three research questions and hypotheses for this study:

1) Are shared English sounds assimilated to the similar Thai sounds? The hypothesis was that the shared vowels in English: /i:, e, æ, s:, u:/ would be assimilated to the same Thai vowels of the same IPA symbols due to the similarity in target-likeness. In other words, the L2 Thai learners would choose the Thai vowels that were represented with similar IPA symbols. The hypothesis on the assimilation patterns for the non-shared English sounds to the closest Thai sounds cannot be generated as there is no study on the English vowels by L2 Thai learners using impressionistic method.

2) To what extent is the perceptual assimilation of shared English vowels vary as a function of language experience? For this hypothesis, it was predicted that no effect of language experience would be found as the shared English vowels also exist in Thai vowel inventory.

3) To what extent does perceptual assimilation of non-shared English vowels vary as a function of language experience? It was hypothesised that the high-experienced group would assimilate them to the closest L1 vowels with less degree of perceived similarity than the low-experienced one. This would suggest that higher L2 experience is correlated with higher ability to distinguish the L2 sounds from the L1 categories.

\section{Method}

\subsection{Subjects}

A total of 55 Thai listeners took part in the study. They were all born in Thailand. The subjects were divided into two groups: high-experienced and low-experienced. The high-experienced group was represented by 27 listeners who were English major students whereas the low-experienced group was 28 listeners who were Computer Science major students. They were the first-year students at Naresuan University. The high-experienced group had received phonetic training for English sounds from English Phonetics and Phonology module. Their ages were 18-19 years old. They reported no speech or hearing disorders and were living in Thailand at the time this study was carried out. As Thailand is the country where English is used as English as a foreign language (EFL), the listeners mainly used English in classrooms. The low-experienced group used English mainly in English modules with grammar-translation method, i.e. having the teacher talks in English followed by the translation in Thai, or explaining to the learners the English grammar in Thai. The high-experienced group received the input mostly in English as English was their major. Their modules were mostly taught by Thai teachers. All subjects volunteered to participate in the study. 


\subsection{Stimuli}

The stimuli consisted of 11 words in English and 13 words in Thai. Each word in English represented one of the following monophthongs: 'beet'/i:/, 'bit'/I/, 'bet'/e/, 'bat'/æ/, 'bot'/p/, 'bart'/a:/, 'bought'/o:/, 'butcher' /o/, 'boot'/u:/, 'but' / $/$ and 'burt'/3:/. For Thai words, they were: 'บิด'/i/, ‘บีด'/i:/, 'เบ็ด'/e/, 'เบด’/e:/, 'แบ็ด' /æ/,

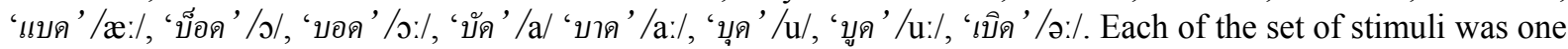
block. The target vowels were in $/ \mathrm{b} /-\mathrm{V}-/ \mathrm{t} /$ context. Some of them were nonsense words. The English stimuli were produced by three native speakers of British English. One was born in Norwich; the second was born in Oxford and the last one was born in Birmingham. Their ages were between 34-36 years old. For the Thai stimuli, they were produced by three native speakers of Thai who were born in Loei, Sukhothai and Chachoengsao. Their ages were between 36-49 years old. All of them were male and were living in Thailand at the time this study was carried out. Each of them produced the stimuli five times in carrier phases: 'Say_ again.' for English and /phê.t.wa:__ì:k.k'rán/ 'Say __ again' for Thai. They reported no speech and hearing problems. Their voices were recorded using a Zoom: $\mathrm{H} 4 \mathrm{n}$ Pro recorder. The recordings were in stereo at a $44.1 \mathrm{kHz}$ (16-bit quantisation). The recordings were made in the soundproofed meeting room at Naresuan University.

\subsection{Data Collection}

The data collection took place in a computer room at Naresuan University, Thailand. The perceptual assimilation experiment was run with script on Praat MFC (Boersma \& Weenink, 2016) on a PC computer. Each listener had a headphone to listen to the stimuli. On the screen, the instruction was: 'You will hear a consonant-vowel-consonant sequence. The first consonant is ' $b$ ' sound and the second consonant is ' $t$ ' sound. Pay attention to the vowel sound and choose the Thai vowel that is most similar to the sound you heard. Then rate the similarity of the Thai sound to the sound you heard on a scale from 1 (very different) to 7 (very similar). The number of trials is 360 , and you can break every 50 trials. You can see how far you are from the left top corner of the screen. To continue, click the mouse.' The instruction was in Thai to minimise language barrier. The number of the English stimuli to hear was 165 (11 monophthongs $\mathrm{x} 3$ speakers $\mathrm{x} 5$ times) and the number of the Thai stimuli was 195 (13 monophthongs $\mathrm{x} 3$ speakers $\mathrm{x} 5$ times). The listeners chose their answer by clicking

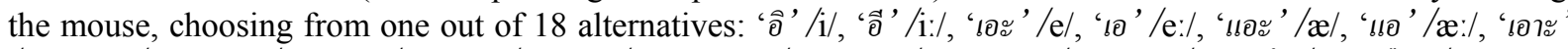

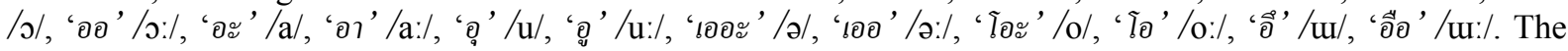
alternatives were in Thai letters only - no IPA symbols were provided. If they would like to hear the stimuli again, they could click 'replay' button. After they finished choosing the answer, they clicked 'OK' button to proceed to the next stimulus. The stimuli were randomised with $<$ PermuteBalancedNoDoublets $>$ command in the script. The overall process took approximately 40-45 minutes. This research project received ethical approval from Naresuan University Institutional Review Board (COA No. 010/2019, IRB No. 0877/61).

\subsection{Data Analysis}

The total number of responses from this study was 19800 (360 stimuli x 55 listeners). After recording the responses on Praat, they were transferred to Excel for encoding purpose. The responses from Thai stimuli were excluded from the analysis. Hence, there were 9075 stimuli from the target English monophthongs to be analysed. The data are presented as percentage of the responses for the target English sounds that were matched with the Thai sound categories. Then as suggested by Guion, Flege, Akahane-Yamada, and Pruitt (2000) and Lengeris (2009), the identification data and the goodness-of-fit were combined into a single metric 'the fit index'. The percentage of the classification of each English monophthong to the Thai vowel category was multiplied by 0.01 . For example, when $41.73 \%$ English /æ/ were identified as Thai $/ \mathfrak{m} /$, the value after multiplying by 0.01 was 0.4173 . Then this value was multiplied with the goodness of fit for each response for that Thai monophthong. The interpretation of this fit index is that the fit index value correspondingly increases with perceived similarity between the target L2 and matched L1 sounds.

To find out whether there were significant differences in the perceived similarity of the most-frequently-identified L1 sound with the target L2 sounds, and the effect of the L2 experience, linear mixed model (LMM) using the lme4 package (Bates, Maechler, Bolker, \& Walker, 2015) was run in RStudio statistical software (RStudio Team, 2017). The dependent variable was the fit index. The independent variables were as follows: L2 experience (high-experienced and low-experienced) and the combination of target vowel and response. The analysis was carried out on Thai categories which had a significant number of matches. Matches, in percentage terms, showed that most of the target English monophthongs had one most-frequently-identified Thai sound. This was followed by English /i:/ which had two Thai responses, i.e. /i/ and /i:/. English /u:/ also had two Thai responses that were comparable but only to the low-experienced group, i.e. Thai $/ \mathrm{u} / / \mathrm{and} / \mathrm{w} /$. The random intercept was listener as there was repetition in observations in them. The optimal model was chosen by 
comparing the models with two-way interaction with one-factor using anova function. These two models were found significantly different from one another. The best model was selected when it had lower Akaike Information Criterion (AIC) than the other (Zhang, 2013). To see the effect of the L2 experience, a post-hoc test was performed with emmeans package (Lenth, Love, \& Herve, 2018) in RStudio statistical software (RStudio Team, 2017). The finding of this LMM is for the prediction of the identification task for English monophthongs.

For the prediction of the discrimination task for English monophthong contrasts, only perceptual assimilation patterns for L2 sounds that had overlapped L1 sound response were run to see whether there was significant difference between them. If the L2 sounds were mapped with two different sounds in L1, there should not be the problem in discriminating L2 sound contrast as the contrast is TC, according to PAM-L2 (Best \& Tyler, 2007). However, when the two sounds in L2 were mapped into one sound, the exploration of whether they were CG or SC assimilation, as suggested by Best and Tyler (2007), was needed. This exploration was done via the other LMM in lme4 package (Bates et al., 2015) with fit index as dependence variable and the combination of the target vowel and the most-frequently-identified L1 category as independent variable. The random intercept was listener. The significant difference of all sound contrasts was presented after running emmeans package (Lenth et al., 2018). If there was significant difference between the perceived similarity of the sound contrasts, then the prediction would be that that pair was CG and the listeners should have no difficulty in discriminating the two sounds. If the perceived similarities of the two sounds was not significantly different from one another, then the pair would be SC suggesting that the listeners should find this contrast difficult to discriminate.

\section{Results}

The results of this study are divided into two parts: the results to generate hypothesis for identification task and the ones for discrimination task.

\subsection{Results for the Hypothesis of Identification Task}

Regarding the hypothesis for the shared sounds that L2 sounds can be assimilated to L1 when both are represented by the same IPA symbol is partially supported by the following results: 1) the English /æ/ was mostly matched with the Thai /æ/ in the high-experienced group; 2) the English /i:/ was mostly matched with the same vowel in the high-experienced group; 3) the English /e/ was mostly matched with the same vowel in both groups; and 4) the English /u:/was mostly matched with the same vowel in the high-experienced group. However, this hypothesis was not supported in the following results: 1) the English /æ/ was mostly matched with the Thai /a/ in the low-experienced group; 2) the English /i:/ was mostly matched with the Thai /i/ in the low-experienced group; 3) the English /u:/ was mostly matched with the Thai /u/ in the low-experienced group; and 4) the English /o:/ was mostly matched with the Thai /o:/ in both groups. The results of the assimilation patterns and the mean of fit index can be seen in Table 1 (for high-experienced group) and Table 2 (for low-experienced group). 
Table 1. Percentage of the perceptual assimilation patterns of English sounds to Thai sounds and mean fit index in parenthesis for the learners with high experience. Bold percentage for the most-frequently-identified matching

\begin{tabular}{|c|c|c|c|c|c|c|c|c|c|c|c|}
\hline & /a:/ & $/ æ /$ & /i:/ & /e/ & $/ \mathrm{I} /$ & /u:/ & $/ \mathrm{p} /$ & $10: /$ & $13: /$ & $/ \Lambda /$ & $/ \mho /$ \\
\hline \multirow[t]{2}{*}{$/ \mathfrak{m} /$} & & $41.73 \%$ & & $16.05 \%$ & $1.73 \%$ & & & & & $0.49 \%$ & \\
\hline & - & $(1.37)$ & - & $(0.53)$ & $(0.05)$ & - & - & - & - & $(0.01)$ & - \\
\hline \multirow[t]{2}{*}{ /æ:/ } & & $7.65 \%$ & & $1.48 \%$ & & & & & & & \\
\hline & - & $(0.27)$ & - & $(0.06)$ & - & - & - & - & - & - & - \\
\hline \multirow[t]{2}{*}{ /e/ } & & $2.47 \%$ & & $58.02 \%$ & $16.30 \%$ & & & & $1.73 \%$ & $0.25 \%$ & $0.74 \%$ \\
\hline & - & $(0.07)$ & - & $(2.03)$ & $(0.68)$ & - & - & - & $(0.08)$ & $(0.01)$ & $(0.04)$ \\
\hline \multirow[t]{2}{*}{ /e:/ } & & $0.25 \%$ & & $8.15 \%$ & & & $0.25 \%$ & & $1.23 \%$ & $0.25 \%$ & \\
\hline & - & $(0.01)$ & - & $(0.27)$ & - & - & $(0.01)$ & - & $(0.05)$ & $(0.00)$ & - \\
\hline \multirow[t]{2}{*}{ /i/ } & & & $49.14 \%$ & $0.49 \%$ & $78.77 \%$ & $1.23 \%$ & & & & $0.25 \%$ & $0.25 \%$ \\
\hline & - & - & (1.82) & $(0.00)$ & $(2.57)$ & $(0.04)$ & - & - & - & $(0.00)$ & $(0.00)$ \\
\hline \multirow[t]{2}{*}{ /i:/ } & $0.25 \%$ & & $50.86 \%$ & & $2.96 \%$ & $0.25 \%$ & & & & & \\
\hline & $(0.00)$ & - & $(1.72)$ & - & $(0.09)$ & $(0.01)$ & - & - & - & - & - \\
\hline \multirow[t]{2}{*}{$\mid 0 /$} & $17.28 \%$ & & & $0.25 \%$ & & & $37.78 \%$ & $0.74 \%$ & $0.74 \%$ & $17.04 \%$ & \\
\hline & $(0.53)$ & - & - & $(0.01)$ & - & - & $(1.16)$ & $(0.01)$ & $(0.03)$ & $(0.55)$ & - \\
\hline \multirow[t]{2}{*}{$10: /$} & $22.96 \%$ & $0.25 \%$ & & & & $0.25 \%$ & $22.96 \%$ & $6.67 \%$ & $0.25 \%$ & $0.99 \%$ & \\
\hline & $(0.75)$ & $(0.00)$ & - & - & - & $(0.00)$ & $(0.66)$ & $(0.21)$ & $(0.00)$ & $(0.03)$ & - \\
\hline \multirow[t]{2}{*}{ /o:/ } & & $0.25 \%$ & & $0.25 \%$ & & & $2.22 \%$ & $68.64 \%$ & & & \\
\hline & - & $(0.00)$ & - & $(0.02)$ & - & - & $(0.05)$ & $(2.20)$ & - & - & - \\
\hline \multirow[t]{2}{*}{ /o/ } & $0.49 \%$ & & & & & $0.25 \%$ & $33.33 \%$ & $23.46 \%$ & & $0.49 \%$ & $0.74 \%$ \\
\hline & $(0.02)$ & - & - & - & - & $(0.02)$ & $(0.88)$ & $(0.64)$ & - & $(0.01)$ & $(0.02)$ \\
\hline \multirow[t]{2}{*}{ /a/ } & $3.46 \%$ & $31.11 \%$ & & & & & $0.25 \%$ & & $0.49 \%$ & $39.51 \%$ & $0.74 \%$ \\
\hline & $(0.13)$ & $(1.11)$ & - & - & - & - & $(0.00)$ & - & $(0.01)$ & $(1.05)$ & $(0.01)$ \\
\hline \multirow[t]{2}{*}{ /w/ } & & & & & & $5.68 \%$ & & & & & $9.63 \%$ \\
\hline & - & - & - & - & - & $(0.16)$ & - & - & - & - & $(0.29)$ \\
\hline \multirow[t]{2}{*}{ |a/ } & $3.46 \%$ & $1.48 \%$ & & $14.57 \%$ & $0.25 \%$ & & $2.96 \%$ & $0.25 \%$ & $39.26 \%$ & $38.77 \%$ & $7.16 \%$ \\
\hline & $(0.13)$ & $(0.05)$ & - & $(0.41)$ & $(0.01)$ & - & $(0.08)$ & $(0.02)$ & $(1.36)$ & $(1.10)$ & $(0.22)$ \\
\hline \multirow[t]{2}{*}{$/ \mathrm{u} /$} & & & & & & $26.17 \%$ & $0.25 \%$ & & & & $76.30 \%$ \\
\hline & - & - & - & - & - & $(0.68)$ & $(0.00)$ & - & - & - & $(2.39)$ \\
\hline \multirow[t]{2}{*}{ /a:/ } & $51.60 \%$ & $14.32 \%$ & & $0.25 \%$ & & $0.25 \%$ & & & & $0.74 \%$ & \\
\hline & (1.44) & $(0.48)$ & - & $(0.00)$ & - & $(0.02)$ & - & - & - & $(0.01)$ & - \\
\hline \multirow[t]{2}{*}{ /w:/ } & & $0.25 \%$ & & & & $1.98 \%$ & & & & & $0.25 \%$ \\
\hline & - & $(0.00)$ & - & - & - & $(0.05)$ & - & - & - & - & $(0.01)$ \\
\hline \multirow[t]{2}{*}{ /a:/ } & $0.49 \%$ & $0.25 \%$ & & $0.49 \%$ & & & & & $56.30 \%$ & $1.23 \%$ & $0.25 \%$ \\
\hline & $(0.01)$ & $(0.01)$ & - & $(0.03)$ & - & - & - & - & $(1.97)$ & $(0.04)$ & $(0.01)$ \\
\hline \multirow[t]{2}{*}{ /u:/ } & & & & & & $63.95 \%$ & & $0.25 \%$ & & & $3.95 \%$ \\
\hline & - & - & - & - & - & $(1.74)$ & - & $(0.01)$ & - & - & $(0.11)$ \\
\hline
\end{tabular}


Table 2. Percentage of the perceptual assimilation patterns of English sounds to Thai sounds and mean fit index in parenthesis for the learners with low experience. Bold percentage for the most-frequently-identified matching

\begin{tabular}{|c|c|c|c|c|c|c|c|c|c|c|c|}
\hline & /a:/ & $/ \mathfrak{m} /$ & /i:/ & /e/ & $/ \mathrm{I} /$ & /u:/ & $/ \mathrm{p} /$ & /o:/ & /3:/ & $\mid \mathrm{s} /$ & $/ \mathrm{J} /$ \\
\hline \multirow[t]{2}{*}{$/ \mathfrak{a} /$} & $0.48 \%$ & $28.33 \%$ & & $34.05 \%$ & $3.57 \%$ & $0.24 \%$ & $1.19 \%$ & & $2.86 \%$ & $2.62 \%$ & $0.71 \%$ \\
\hline & $(0.03)$ & $(1.02)$ & - & $(1.29)$ & $(0.17)$ & $(0.01)$ & $(0.05)$ & - & $(0.12)$ & $(0.11)$ & $(0.02)$ \\
\hline \multirow[t]{2}{*}{ /æ:/ } & $0.24 \%$ & $8.81 \%$ & & $6.43 \%$ & $0.24 \%$ & & $0.24 \%$ & $0.48 \%$ & $0.48 \%$ & & \\
\hline & $(0.00)$ & $(0.24)$ & - & $(0.22)$ & $(0.01)$ & - & $(0.01)$ & $(0.02)$ & $(0.02)$ & - & - \\
\hline \multirow[t]{2}{*}{ /e/ } & $0.71 \%$ & $3.10 \%$ & $0.48 \%$ & $34.76 \%$ & $23.81 \%$ & $0.71 \%$ & $0.95 \%$ & & $1.43 \%$ & $2.62 \%$ & $0.95 \%$ \\
\hline & $(0.04)$ & $(0.13)$ & $(0.03)$ & $(0.99)$ & $(0.77)$ & $(0.03)$ & $(0.05)$ & - & $(0.05)$ & $(0.09)$ & $(0.03)$ \\
\hline \multirow[t]{2}{*}{ /e:/ } & $0.24 \%$ & $0.71 \%$ & $0.24 \%$ & $8.33 \%$ & $3.10 \%$ & $0.24 \%$ & & & $1.43 \%$ & $0.48 \%$ & $0.24 \%$ \\
\hline & $(0.01)$ & $(0.02)$ & $(0.01)$ & $(0.23)$ & $(0.09)$ & $(0.01)$ & - & - & $(0.05)$ & $(0.02)$ & $(0.00)$ \\
\hline \multirow[t]{2}{*}{ /i/ } & & & $60.24 \%$ & & $59.52 \%$ & $4.52 \%$ & & & $0.24 \%$ & & $0.24 \%$ \\
\hline & - & - & $(2.42)$ & - & (1.98) & $(0.20)$ & - & - & $(0.01)$ & - & $(0.00)$ \\
\hline \multirow[t]{2}{*}{ /i:/ } & & & $36.90 \%$ & $0.24 \%$ & $2.38 \%$ & $0.48 \%$ & $0.24 \%$ & & & & \\
\hline & - & - & $(1.07)$ & $(0.01)$ & $(0.08)$ & $(0.00)$ & $(0.00)$ & - & - & - & - \\
\hline \multirow[t]{2}{*}{$/ 0 /$} & $20.95 \%$ & $1.19 \%$ & & $1.19 \%$ & $1.19 \%$ & $0.24 \%$ & $17.14 \%$ & & $0.95 \%$ & $16.43 \%$ & $0.95 \%$ \\
\hline & $(0.97)$ & $(0.06)$ & - & $(0.07)$ & $(0.05)$ & $(0.00)$ & $(0.51)$ & - & $(0.06)$ & $(0.57)$ & $(0.05)$ \\
\hline \multirow[t]{2}{*}{$10: /$} & $20.48 \%$ & & & $0.24 \%$ & $0.24 \%$ & $0.24 \%$ & $18.10 \%$ & $2.86 \%$ & & $2.38 \%$ & $0.24 \%$ \\
\hline & $(0.59)$ & - & - & $(0.02)$ & $(0.00)$ & $(0.01)$ & $(0.52)$ & $(0.08)$ & - & $(0.05)$ & $(0.02)$ \\
\hline \multirow[t]{2}{*}{ /o:/ } & $0.48 \%$ & $0.24 \%$ & & & $0.24 \%$ & $0.71 \%$ & $7.38 \%$ & $\mathbf{5 8 . 5 7 \%}$ & $0.24 \%$ & & \\
\hline & $(0.02)$ & $(0.01)$ & - & - & $(0.01)$ & $(0.02)$ & $(0.18)$ & $(1.82)$ & $(0.01)$ & - & - \\
\hline \multirow[t]{2}{*}{ /o/ } & $2.62 \%$ & $0.95 \%$ & $0.24 \%$ & & $0.71 \%$ & $0.71 \%$ & $48.57 \%$ & $30.24 \%$ & $1.43 \%$ & $3.10 \%$ & $2.14 \%$ \\
\hline & $(0.11)$ & $(0.04)$ & $(0.00)$ & - & $(0.04)$ & $(0.02)$ & $(1.86)$ & $(1.18)$ & $(0.05)$ & $(0.13)$ & $(0.07)$ \\
\hline \multirow[t]{2}{*}{$/ \mathrm{a} /$} & $4.05 \%$ & $44.29 \%$ & & $0.48 \%$ & & & & $0.24 \%$ & & $32.14 \%$ & $0.48 \%$ \\
\hline & $(0.16)$ & $(1.90)$ & - & $(0.02)$ & - & - & - & $(0.01)$ & - & $(0.82)$ & $(0.02)$ \\
\hline \multirow[t]{2}{*}{$/ \mathrm{w} /$} & $0.24 \%$ & & $0.48 \%$ & $0.24 \%$ & $1.19 \%$ & $32.62 \%$ & $0.48 \%$ & & $0.24 \%$ & & $10.71 \%$ \\
\hline & $(0.02)$ & - & $(0.03)$ & $(0.01)$ & $(0.05)$ & $(1.41)$ & $(0.03)$ & - & $(0.01)$ & - & $(0.45)$ \\
\hline \multirow[t]{2}{*}{ /a/ } & $5.00 \%$ & $2.14 \%$ & $0.71 \%$ & $12.86 \%$ & $1.90 \%$ & $0.71 \%$ & $4.52 \%$ & $0.71 \%$ & $36.19 \%$ & $29.05 \%$ & $11.19 \%$ \\
\hline & $(0.21)$ & $(0.08)$ & $(0.03)$ & $(0.48)$ & $(0.07)$ & $(0.02)$ & $(0.13)$ & $(0.05)$ & $(1.43)$ & $(0.87)$ & $(0.36)$ \\
\hline \multirow[t]{2}{*}{$/ \mathrm{u} /$} & & & & & & $15.48 \%$ & & $0.48 \%$ & & & $63.57 \%$ \\
\hline & - & - & - & - & - & $(0.43)$ & - & $(0.00)$ & - & - & (1.95) \\
\hline \multirow[t]{2}{*}{ /a:/ } & $42.38 \%$ & $8.81 \%$ & & & & & & & & $0.71 \%$ & \\
\hline & $(1.23)$ & $(0.27)$ & - & - & - & - & - & - & - & $(0.02)$ & - \\
\hline \multirow[t]{2}{*}{ /w:/ } & & & $0.48 \%$ & & $0.48 \%$ & $11.43 \%$ & & & & & \\
\hline & - & - & $(0.01)$ & - & $(0.02)$ & $(0.43)$ & - & - & - & - & - \\
\hline \multirow[t]{2}{*}{ /a:/ } & $1.90 \%$ & $1.43 \%$ & $0.24 \%$ & $1.19 \%$ & $1.19 \%$ & $0.95 \%$ & $1.19 \%$ & $0.48 \%$ & $54.29 \%$ & $10.48 \%$ & $2.14 \%$ \\
\hline & $(0.08)$ & $(0.05)$ & $(0.01)$ & $(0.04)$ & $(0.03)$ & $(0.04)$ & $(0.05)$ & $(0.02)$ & $(1.87)$ & $(0.25)$ & $(0.07)$ \\
\hline \multirow[t]{2}{*}{ /u:/ } & $0.24 \%$ & & & & $0.24 \%$ & $30.71 \%$ & & $5.95 \%$ & $0.24 \%$ & & $6.43 \%$ \\
\hline & $(0.00)$ & - & - & - & $(0.01)$ & $(0.69)$ & - & $(0.17)$ & $(0.01)$ & - & $(0.16)$ \\
\hline
\end{tabular}

For the non-shared sounds, although there was no hypothesis for these sounds, the results of high-experienced and low-experienced groups are mostly similar as follows: the English /a:/ was mostly matched to Thai /a:/; the English /I/ was mostly matched with Thai /i/; the English /3:/ was mostly matched with Thai /a:/; the English / $/$ / was mostly matched with Thai /a/; and the English / / / was mostly matched with Thai /u/. The difference in the 
assimilation pattern between these two groups was in the perception of the English / $\mathfrak{p} /$ that was mostly matched with Thai / $/ 0$ in the high-experienced group and with Thai /o/ in the low-experienced group. These findings suggest that L2 Thai learners benefits the perceptual assimilation patterns from the durational quality of the vowels in L1 and L2, i.e. the short monophthongs in English were matched with the short monophthongs in Thai, and the long monophthongs in English were mostly matched with the long monophthongs in Thai across L2 experience. They also suggest that the high-experienced group benefited from the durational quality of the Thai monophthongs to a higher degree than the low-experienced group - all long British English vowels were mostly matched with long Thai vowels, and all short vowels in L2 were also matched with short Thai vowels in the high-experienced group. For the low experienced-group, although all short vowels in British English were matched with short vowels in Thai, not all long vowels in British English were matched with long vowels in Thai.

As the hypothesis regarding the effect of the L2 experience is divided into two types: for shared sounds and for non-shared sounds, the results are presented as follows. For the shared sounds, it was predicted that the L2 experience would not have an effect on the degree of perceived similarity between the L1 and L2 sounds. This is true in the following contrasts: 1) in the perceived similarity of English /æ/ and Thai /æ/ in the high-experienced group, and of English /æ/ and Thai /a/ in the low-experienced group; 2) in the perceived similarity of English /i:/ and Thai /i:/ in the high-experienced group, and of English /i:/ and Thai /i/ in the low-experienced group; 3 ) in the perceived similarity of English /u:/ as Thai /u// in the low-experienced group, and of English / $\mathrm{u}: /$ as Thai /u:/ in the high-experienced group; and 4) in the perceived similarity of English / $0: /$ as Thai /o:/ in both groups ( $p>$ 0.05 for all contrasts). However, this hypothesis is not supported in the following contrasts: 1 ) in the perceived similarity of English /e/ and Thai /e/ in both groups as the high-experienced group perceived this English sound as significantly more similar to Thai /e/ than the low-experienced group $(b=0.92, S E=0.19, d f=104.47, t=$ $4.89, p<0.01)$; and 2) in the perceived similarity of English /u:/, this sound was perceived as significantly more similar to Thai /u:/ in the high-experienced group than in the low-experienced group $(b=0.91, S E=0.19, d f=$ $107.88, t=4.76, p<0.01$ ).

For the non-shared sounds, it was predicted that the low-experienced group would perceive the target English sound as similar to the Thai sound more than the high-experienced group. This hypothesis was mostly contrastive as there were no significant differences in the degree of perceived similarity in both groups in the following matchings: 1) between English /a:/ and Thai /a:/; 2) between English /I/ and Thai /i/; 3) between English /3:/ and Thai /o:/; 4) between English / $/$ and Thai /a/; and 5) between English / $/ /$ and Thai $/ \mathrm{u} /(p>0.05$ for all contrasts). The only result that supports this hypothesis is that English $/ \mathfrak{p} /$ was perceived as Thai $/ \mathrm{o} /$ in the low-experienced group in higher degree than as Thai /o/ in the high-experienced group $(b=-0.72, S E=0.19, d f$ $=106.52, t=-3.79, p<0.05$ ).

The hypotheses for the identification task from these findings are divided into shared and non-shared sounds. The hypotheses for the shared English sounds are as follows. For English /æ/, /i:/ and /u:/, the high-experienced group will have higher score of correct identification than the low-experienced group as they mostly selected the Thai sounds represented with the same IPA symbols whereas the low-experienced group mostly matched these sounds to the other monophthongs in Thai. For English /e/, as both groups mostly matched this sound with Thai /e/, the correct identification score for this English vowel should be high regardless of the degree of L2 experience; however, the high-experienced group should receive lower score of correct identification than the low-experienced group as they perceived this sound to be more similar to Thai /e/ than the low-experienced one. For English $/ \mathrm{s}: /$, both groups should have low score of correct identification as they mostly identified this sound as Thai /o:/ with no significant difference in the scores of the fix index.

For non-shared sounds, the hypotheses are as follows. Regarding English /a:, I, 3:, $\Lambda, \mho /$, both groups were not different in mostly matching the Thai vowels. Their correct identification scores for these target English monophthongs should be high as the fit indexes of these vowels to the closest Thai monophthongs were less than 3.5 out of 7. This suggests that the L2 learners can perceive the difference between Thai and English monophthongs. For English / $/ \mathrm{b}$, it is predicted that the low-experienced group should receive lower correct identification score than the high-experienced group because they mostly perceived this sound as Thai /o/ in greater degree than the high-experienced group who mostly matched this sound with Thai $/ \mathrm{o} /$.

\subsection{Results for the Hypothesis of Discrimination Task}

For the hypothesis for the discrimination task based on the results of the perceptual assimilation task, it is predicted that there will not be difficulty in discriminating the sound pairs in English for the high-experienced group as all the English vowels were matched with different Thai vowels. Table 1 shows that the 
high-experienced group had no overlapped Thai category for different target English monophthongs. The sound contrasts that are expected to cause difficulty in discrimination in the high-experienced group cannot be generated from this group.

For the low-experienced group, they should not have difficulty discriminating most sound pairs. However, Table 2 shows that the low-experienced group perceived English /i:///// as the most similar to Thai /i/, and English $/ æ / / / \Lambda /$ as the most similar to Thai /a/. This suggests that they might have difficulty in discriminating the following vowel pairs: 1) English /i:/ and /I/ they were mostly matched to the Thai /i/; and 2) English /æ/ and / $/$ as they were mostly matched with the Thai $/ \mathrm{a} /$. The responses of these two pairs were explored to see whether the pair was CG or SC, according to PAM-L2 (Best \& Tyler, 2007). To decide whether these two pairs are SC or CG, LMM was run as described in the data analysis. The results from LMM showed that in the low-experienced group, they significantly perceived English /i:/ as more similar to Thai /i/ than English /I/ $(b=0.37, S E=0.10, d f$ $=808.44, t=3.82, p<0.01)$, and they also significantly perceived English $/ \mathfrak{a} /$ as more similar to Thai /a/ than English $/ \mathrm{A} /(b=1.02, S E=0.12, d f=807.88, t=8.43, p<0.01)$. This suggests that both pairs are $\mathrm{CG}-$ the low-experienced group should not have difficulty in discriminating these two vowel contrasts as the findings suggest they could discern the difference between the two sounds.

\section{Discussion and Conclusion}

Although some results are contrastive to the concept of the importance of the L2 experience in the L2 speech learning, many of them support this idea as shown in many previous studies (e.g., Kitikanan, 2017; Levy, 2009). For example, English /æ/ was mostly perceived as Thai /æ/ in the high-experienced group, but as Thai /a/ in the low-experienced group. The other example is from the assimilation pattern of English / $\mathfrak{p} /$ that was mostly matched with Thai $/ \mathrm{J} /$ in the high-experienced group and with Thai /o/ in the low-experienced group. Even though Thai has higher number of monophthongs than English, it does not mean all learners will benefit from this variability in the assimilation patterns in the same degree. They suggest that in the exploration of the L2 sound learning, the experience in the L2 should be taken into account. In other words, the findings of this study support that L2 experience is paramount to the higher number of phonemes in the same category in L1 as compared to that in L2.

Regarding the implication of this study to the L2 teaching, when teaching the L2 vowels to the L2 learners, the teacher should also take the experience in L2 of the learners in the selection of the teaching method. The higher number of phonemes in L1 in the same category than that of phonemes in L2, such as having higher number of L1 vowels than that of L2 vowels, is not always useful to the L2 learners. When the L2 learners have low experience in learning the L2, the teacher might need to provide activities, such as comparing the number of the L1 sounds to the closest L2 sounds to increase the number of L2 sounds in the phonological system of the L2 learners.

For the limitations, as the target English monophthongs were in only one contexts, i.e. /bVt/, the pattern of the perceptual assimilation of these sounds to the closest Thai sounds might be different in the other contexts, as shown in the study of Strange, Akahane-Yamada, Kubo, Trent, and Nishi (2001) and Levy (2009) that the context of the target sounds also plays role in the assimilation pattern of L2 vowels. Future project might include more contexts containing English monophthongs, such as English monophthongs in bilabial context as compared to those in alveolar context to investigate the assimilation patterns of them with the closest L1 sounds by L2 learners. The other limitation is that the listeners of this study were L2 Thai learners in EFL context. By adding learners with different language backgrounds, such as comparing L2 learners in EFL context to English as a second language (ESL) context might show that the linguistic background of the L2 learners also accounts for the perceptual assimilation of the L2 sounds to the L1 sound categories.

\section{References}

Bates, D., Maechler, M., Bolker, B., \& Walker, S. (2015). Fitting Linear Mixed-Effects Models Using lme4. . Journal of Statistical Software, 67(1), 1-48. https://doi.org/10.18637/jss.v067.i01

Best, C. T. (1995). A direct realist perspective on cross-language speech perception. In W. Strange (Ed.), Speech perception and linguistic experience: Issues in cross-language research (pp. 171-204). Timonium, MD: York Press.

Best, C. T., \& Tyler, M. D. (2007). Nonnative and second-language speech perception: Commonalities and complementarities. In M. J. Munro \& O.-S. Bohn (Eds.), Second language speech learning: The role of language experience in speech perception and production (pp. 13-34). Amsterdam: John Benjamins. https://doi.org/10.1075/11lt.17.07bes 
Boersma, P., \& Weenink, D. (2016). Praat, a system for doing phonetics by computer (Version Version 6.0.19). Retrieved from http://www.praat.org/

Cebrian, J. (2019). Perceptual assimilation of British English vowels to Spanish monophthongs and diphthongs. The Journal of the Acoustical Society of America, 145(1), EL52-EL58. https://doi.org/10.1121/1.5087645

Escudero, P. (2009). Linguistic perception of "similar" L2 sounds. Phonology in perception, 15, 152-190.

Flege, J. E. (1995). Second language speech learning: Theory, findings, and problems. Speech perception and linguistic experience: Issues in cross-language research, 233-277.

Guion, S. G., Flege, J. E., Akahane-Yamada, R., \& Pruitt, J. C. (2000). An investigation of current models of second language speech perception: The case of Japanese adults' perception of English consonants. The Journal of the Acoustical Society of America, 107(5), 2711-2724. https://doi.org/10.1121/1.428657

Kallayanamit, S. (2010). Perception of American English vowels by standard Thai native speakers. Journal of Humanities, Naresuan University, 7(3), 63-98.

Kallayanamit, S. (2016). Production of English vowel duration in monosyllabic words by Thai learners of English and its intelligibility. Journal of Humanities, Naresuan University, 13(2), 1-26.

Kitikanan, P. (2017). The Effects of L2 Experience and Vowel Context on the Perceptual Assimilation of English Fricatives by L2 Thai Learners. English Language Teaching, 10(12), 72. https://doi.org/10.5539/elt.v10n12p72

Lengeris, A. (2009). Perceptual assimilation and L2 learning: Evidence from the perception of Southern British English vowels by native speakers of Greek and Japanese. Phonetica, 66(3), 169-187. https://doi.org/10.1159/000235659

Lenth, R., Love, J., \& Herve, M. (2018). emmeans: Estimated Marginal Means, aka Least-Squares Means. Retrieved from https://CRAN.R-project.org/package=emmeans

Levy, E. S. (2009). Language experience and consonantal context effects on perceptual assimilation of French vowels by American-English learners of French. The Journal of the Acoustical Society of America, 125(2), 1138-1152. https://doi.org/10.1121/1.3050256

Nusartlert, A., \& Tongpoonpatanasorn, A. (2015). Vowel production and perception of English back vowels in Thai adult EFL learners. Journal of Graduate Study in Humanities and Social Sciences, 4(1), 31-52.

Roach, P. (2004). British English: Received Pronunciation. Journal of the International Phonetic Association, 34(2), 239-245. https://doi.org/10.1017/S0025100304001768

RStudio Team. (2017). RStudio: Integrated Development for R. Boston, MA. Retrieved from http://www.rstudio.com/

Strange, W., Akahane-Yamada, R., Kubo, R., Trent, S. A., \& Nishi, K. (2001). Effects of consonantal context on perceptual assimilation of American English vowels by Japanese listeners. The Journal of the Acoustical Society of America, 109(4), 1691-1704. https://doi.org/10.1121/1.1353594

Strange, W., Bohn, O.-S., Trent, S. A., \& Nishi, K. (2004). Acoustic and perceptual similarity of North German and American English vowels. The Journal of the Acoustical Society of America, 115(4), 1791-1807. https://doi.org/10.1121/1.1687832

Tsukada, K. (2009). Durational characteristics of English vowels produced by Japanese and Thai second language (L2) learners. Australian Journal of Linguistics, 29(2), 287-299. https://doi.org/10.1080/07268600902823144

Zhang, X. (2013). Foreign language listening anxiety and listening performance: Conceptualizations and causal relationships. System, 4l(1), 164-177. https://doi.org/10.1016/j.system.2013.01.004

\section{Copyrights}

Copyright for this article is retained by the author(s), with first publication rights granted to the journal.

This is an open-access article distributed under the terms and conditions of the Creative Commons Attribution license (http://creativecommons.org/licenses/by/4.0/). 